\title{
AS FLANÂNCIAS URBANAS DE SOPHIE CALLE: REFLEXÕES ENTRE PÚBLICO E PRIVADO
}

\author{
Carolina Gallo Garcia ${ }^{1}$
}

\section{Introdução}

Este trabalho se origina como parte de minha pesquisa de mestrado, na qual busquei produzir uma reflexão acerca da noção de espaço público a fím de disputar o conceito. Em um primeiro nível de argumentação, tratei de lançar luz à dimensão de gênero presente na acepção dominante de espaço público ao questionar os históricos paradigmas modernos da dicotomia público-privada enquanto tecnologia de produção de espaços generificados tradicionalmente cindida entre homens-públicos e mulheresprivadas $^{2}$. Na dissertação (Garcia, 2018) uma discussão sobre a instauração destas esferas separadas é tratada à luz da história, geografia e teoria feministas, bem como dos recentes estudos que associam as teorias de gênero às reflexões do campo da arquitetura e urbanismo. Em um segundo nível de discussão, recorri a refletir de que modos um modelo agonístico de democracia, preconizado por Chantal Mouffe (2013), poderia ser formulado a partir de práticas artísticas críticas que evidenciam o caráter sempre dissensual e disputado do espaço público.

Assim, ao considerar a noção de espaço público enquanto lócus de disputas, explorei como uma arte crítica (Mouffe, 2013; Rancière, 2012; Deutsche, 2008) produzida em espaços urbanos por artistas mulheres desponta como possibilidade de produção de dissensos (Rancière, 1996) que tornam visíveis os limites da noção hegemônica e consensual pressuposta nos termos de "espaço público" como algo dado de antemão. Neste trabalho, tomo como objeto de análise as imagens produzidas em performances realizadas nas décadas de 1980 e 1990 pela artista francesa Sophie Calle (1953) especificamente nos espaços públicos urbanos, considerando-os registros que interpreto como uma atualização de cunho feminista da flânerie baudelariana. A partir de performances transcorridas nas ruas de Paris, Veneza e Nova Iorque, estas resultam como modo de tramar relações visuais e teóricas que permitem pensar uma dimensão crítica e

\footnotetext{
${ }^{1}$ Universidade Estadual de Campinas, Brasil. Email: carolinagarcia3@gmail.com ORCID id: http://orcid.org/0000-0003-3702-6098

2 Para uma reflexão sobre o culto da domesticidade enquanto tecnologia de distinção social instaurada para mulheres das classes médias e burguesas na era vitoriana, ver McClintock (2010).
} 
contestadora destas ações. Ao engendrarem transgressões, metáforas e ficções (Rancière, 2009), proponho que estes trabalhos permitem novas leituras que subvertem a linguagem tradicional do espaço público nos termos burgueses teorizados por Arendt (2007 [1958]) ou Habermas (1984). Assim, ao preceituar uma radical complexidade espacial por meio de suas poéticas visuais e escritas, que descaracterizam a dicotomia público e privado, tornam as ruas em espaços de disputa que não podem ser apaziguados pelo consenso.

\section{Espaço Público, arte crítica: notas preliminares}

A fim de embasar o argumento deste trabalho, exponho nesta seção alguns pontos teóricos que se apresentam necessários ao debate. A crítica à constituição da dicotomia público-privado foi fundamental às lutas feministas dos séculos XIX e XX, ou, nos termos de Pateman (1989: 118, tradução minha) "em última instância, a base do movimento feminista”. Tal crítica, todavia, adquire contornos mais claros a partir da segunda onda feminista no hemisfério norte, compreendida entre as décadas de 1960 e 1970, que viria trazer uma afirmativa contundente ao debate contemporâneo, "o pessoal é político", evidenciando a resoluta necessidade de abordar a cisão entre vida pública e privada como problema central às dinâmicas de gênero. Embora os termos público e privado se apresentem de modos bastante variados nos debates feministas - com distintas abordagens a partir de espectros liberais, socialistas, interseccionais - os pressupostos de enfrentamento aos termos dicotômicos são insistentes, uma vez que implicam uma ordem binária hierárquica que deve ser constantemente negociada.

Deutsche (2008) atualiza essa discussão ao espaço urbano, exemplificando a estratégia do discurso contemporâneo dominante sobre a "qualidade de vida urbana", no qual tal formulação, em singular, pressupõe igualmente a existência de um habitante urbano genérico, regido por princípios e motivações universalistas. Nesse sentido, o que se verifica é a instauração de uma ordem discursiva de "um espaço cujo caráter público é decretado a priori [...] uma afirmação que inverte a sequência real dos acontecimentos [...] e portanto decretando a priori que usos do espaço público são legítimos" (ibid: 11, tradução minha).

Por sua vez, Mouffe (1992) destaca como a ideia liberal de público e privado baniu ao segundo toda e qualquer diferença, produzindo um eficaz mecanismo de exclusão baseado em toda alteridade que não esteja configurada nos parâmetros normativos de 
homem público; a saber, homens brancos que, ao assumir posição neutra, tornam as demais diferenças visíveis (Dawsey, 2008). Como nos lembram Negt e Kluge (1993), as interações como sujeitos nos espaços públicos dependem das experiências que são possíveis e que estão sempre marcadas pelas desigualdades de acesso e relações de poder. Ao propor a ideia de contra-públicos ${ }^{3}$, os autores sugerem uma esfera pública plural que abarca grupos não-hegemônicos. Sheikh (2004) vai além e sugere que os contra-públicos possam ser lidos a partir do conceito de heterotopia de Foucault (2003), que consistiria em uma utopia localizada, ou mesmo um contra-espaço, cuja existência tende a confrontar e desestabilizar a hegemonia dos espaços estrategicamente estruturados. Assim, o espaço público seria fragmentado por uma pluralidade de espaços que são conflituais e agonísticos entre si. De acordo com a visão desses autores, o público deve ser visto sempre em termos relacionais. A reivindicação de racionalidade e universalidade vai na direção oposta do conceito de contra-público que frequentemente implica na subversão dos espaços arquitetônicos e urbanos para outras práticas, que se reconfiguram pelos usos (Sheikh, 2004).

Assim, enquanto um debate caro aos feminismos e que configura um problema fundamentalmente espacial - a expansão e a redefinição dos termos de espaço público e privado - também destacava-se nas artes a partir da década de 1960. Cortés (2008: 180) destaca como as décadas finais do século XX intensificam a atenção de muitos artistas e arquitetos, que passam a "experimentar meios de transgredir e/ou subverter muitas das tradicionais distinções binárias que organizavam a convivência espacial dos cidadãos". Neste contexto, movimento feminista e movimentos artísticos passam a buscar outras possibilidades de aberturas epistêmicas ao explorar múltiplos modos de dizer, fazer e estar na cidade. Pinho e Oliveira (2012: 57) identificam um imbricado entrelaçamento entre ambos movimentos:

\footnotetext{
A história da performance artística confunde-se com a dos movimentos e teorias feministas, evidenciando-se uma relação simbiótica persistente. A performance autobiográfica feminista é, contudo, a mais consonante com a dimensão política daquilo que é pessoal, explorando criticamente a dialética público/privado, tão significativa para as perspectivas feministas.
}

\footnotetext{
${ }^{3}$ A noção de contra-públicos (counterpublics) também é teorizada por Nancy Fraser (2013). Para a autora, é por meio destes contra-públicos, arenas discursivas produzidas em contestação à noção de um público neutro e unificado, que a esfera pública se torna verdadeiramente pública. Em contraponto à leitura de esfera pública burguesa e unificada, essa visão confronta a teoria racionalista habermasiana, verificando que todo consenso é a construção de modos de dominação e, consequentemente, de exclusão.
} 
É por meio dessa constatação que podemos pensar como as práticas artísticas podem auxiliar na constituição da relação público e privado de modo diferente: ao agenciar fragmentações do espaço público na explicitação dos conflitos sociais, minam o ideal de um público unificado e consensual uma vez que a vida na cidade consiste na experiência de estar sempre sujeito à alteridade como forma de relação social e que enfim conforma o caráter público dos espaços.

A partir de embaralhamentos entre a vida cotidiana e a arte, essas práticas artísticas que tomaram as ruas com evidentes heranças das vanguardas dadaísta, surrealista e situacionista dando origem à arte da performance e ao happening consistem em ações realizadas fora dos espaços expositivos tradicionais e evidenciam a cidade como lócus da política e da produção de resistência à racionalização e mecanização da vida cotidiana. Como argumenta Cidade (2010: 45):

O espaço urbano mais uma vez torna-se o tema e cenário das manifestações artísticas. Diferentemente do movimento impressionista ou das propostas dos artistas do período das vanguardas, quando a cidade tornou-se tema na pintura ou na fotografia, agora o espaço urbano integra e faz parte da própria obra. Torna-se cada vez mais estreita a relação sujeito e espaço, pois ela não se dá somente nas representações planas, mas espaciais, e, sobretudo, contextuais. O espaço físico reúne arquitetura, arte e sujeito no contexto urbano.

Ao tomar a cidade como lócus de produção das relações sociais, esta arte que tomou as ruas é passível de comparação entre a ruptura com os condicionantes da arte moderna - sobretudo aqueles que outorgam a singularidade e a autonomia da obra e do espectador neutro e universal que recebe de modo homogêneo o conteúdo - às rupturas com a ideia de uma esfera pública unificada. Quando a arte contemporânea multiplica seus espaços de aparição, fugindo dos espaços institucionalizados dos museus e das galerias, evidencia que o contexto de produção e circulação das obras pode não ser préfixado, mas antes constantemente negociado. Assim, as práticas contemporâneas operam um duplo movimento de descentralização espacial da obra de arte e do espaço público unívoco, característica que, como veremos a seguir, está sempre presente na obra de Sophie Calle.

Em seu artigo "Quais espaços públicos para práticas de arte crítica?" Chantal Mouffe (2013: 19) nos fala da impossibilidade de pensar arte e política de modo apartados, pois "existe uma dimensão estética na política e uma dimensão política na estética". Para a autora, há uma inseparabilidade entre os campos da arte e da política: antes de serem campos autônomos entre os quais necessitaríamos criar um vínculo, toda prática artística terá dimensão política, uma vez que toda expressão estética atua na 
reprodução ou refutação das ordens simbólicas dominantes. Ou seja: uma vez que as práticas artísticas desempenham um papel na produção e preservação das ordens simbólicas, não é possível pensá-las de modo despolitizado, pois a própria política constitui essas ordens simbólicas das relações sociais. Ainda refletindo sobre as possibilidades da arte, Mouffe (2007: 63) nos recorda que

Toda ordem é a articulação temporária e precária de práticas contingentes. A fronteira entre o social e o político é essencialmente instável e requer deslocamentos e renegociações constantes entre os agentes sociais. As coisas poderiam ser sempre de outro modo [...] pois, ao predicar toda ordem, se excluem outras possibilidades. (Tradução minha)

Reconhecer a dimensão política como antagonismo em latência implica admitir a impossibilidade de um consenso racional conclusivo: toda ordem social estabelecida se apoia na exclusão de outras possibilidades, sendo sempre uma articulação provisória e instável de práticas contingentes (ibid.) Se compreendemos o poder como inerente às relações sociais, então toda ordem social é política e, portanto, baseada em formas de exclusão. Nesse caminho, abre-se a possibilidade de que essas ordens hegemonicamente estabelecidas possam ser desafiadas: toda prática hegemônica é passível de desestruturação em prol de outras formas de articulação.

Ao dar visibilidade e inteligibilidade ao que o senso comum hegemônico busca obliterar, a arte crítica pode proliferar os dissensos. Seja nas pequenas ocupações de espaços urbanos desimportantes, seja no uso não-utilitário da cidade, Calle cumpre a função de visibilizar estas trivialidades.

A partir dessa perspectiva, as artes tanto constituem e preservam determinadas ordens simbólicas quanto são capazes de desafiá-las, e, portanto, serão sempre políticas. Por seu turno, a política é relativa à ordem simbólica das relações sociais, o que evidencia a dimensão estética do próprio corpo social. A arte crítica, nesse entendimento, condiz às práticas dissidentes passíveis de questionar os projetos hegemônicos dominantes ao produzir espaços públicos agonísticos que dão visibilidade ao que está suprimido no aparente consenso.

[...] só reconhecendo a necessidade de uma pluralidade de formas de intervenções, acontecendo numa variedade de espaços públicos, que práticas de arte crítica podem contribuir para a formação de uma variedade de espaços agonísticos, em que uma concepção plural e radical de democracia poderia ser realizada. (Mouffe, 2013: 191) 
De modo bastante semelhante aos contra-públicos, Mouffe (2007) afirma o papel constitutivo das práticas artísticas no espaço público e sua inseparabilidade das possibilidades de democracia radical, vislumbrando-as como intervenções agonistas no espaço que dão visibilidade aos dissensos existentes.

A arte feminista é um exemplo de manifesta preocupação política que, sobretudo desde a década de 1960, vem politizando a construção dos termos público e privado, propondo uma radical revisão da linha que produz a separação dessas esferas. Reckitt e Phelan (2001: 18, tradução minha) destacam que a persistência desse tema na arte produzida por mulheres desde então nos lembram que "a racionalidade nos dá modos de criar categorias, enquanto a arte nos dá formas de resistir a elas". É preciso reconhecer a produção artística feminista como um modo estético e político que não pode ser enquadrada como um movimento ou estilo da história da arte, mas consiste em afirmar novos modos de vida (ibid.).

Podemos argumentar que as artistas mulheres tiveram papel central na consolidação do reconhecimento da indissociabilidade entre estética e política, evidenciando o caráter agonístico intrínseco a toda disputa política por reconhecimento. Reckitt e Phelan (ibid.: 20, tradução minha) afirmam que a arte feminista é a promessa de uma "criação performativa de novas realidades", atraindo-nos aos possíveis do pensamento que ainda devem ser criados e experienciados. Esses novos possíveis irrompem da reorganização de códigos de representação complexos, mas que se referem ao trivial e ao cotidiano, que são característicos das produções feministas. É por essa maneira que caracterizo aqui a obra de Calle enquanto um conjunto de performances feministas, ainda que a autora não necessariamente classifique seu trabalho desta forma. Todavia, suas obras problematizam os binarismos, utilizam-se da arte para atravessar as fronteiras do público e privado e evidenciam que toda identidade é necessariamente inacabada, uma performance sempre em processo (ibid.).

\section{Pensar o dissenso: Da polícia à política da arte}

Uma vez apresentado até aqui diversos autores que contestam a noção de consenso, cabe conceitualizar o que proponho em seu lugar: o dissenso. A partir de Rancière (2006), a definição consensual da razão política nos dias de hoje é inseparável aos modos de racionalidade intrínsecos da política, sendo o dissenso, portanto, aquilo que o autor nomeia como a racionalidade política per se: 
[...] a razão política, a razão dissensual tal como procuro defini-la, tem a especificidade de estar sempre à beira de seu desaparecimento. Essa razão, com efeito, não é a razão dos Estados, não é a dos indivíduos ou grupos que buscam se entender para otimizar seus interesses respectivos. É a razão de atores ocasionais e intermitentes que constroem aquelas cenas singulares em que o próprio conflito é o que produz uma comunidade. Essa razão está, assim, cercada de abismos, sempre ameaçada a desaparecer. (ibid.: 381 )

Resgatando as origens gregas do termo democracia enquanto o poder do povo daqueles que não dispõem de títulos ou poder para governar - Rancière (2006) nos lembra que a instauração democrática se fundamenta no princípio da igualdade e da ruptura com quaisquer lógicas de dominação existentes. Tal paradoxo é precisamente onde se situa a racionalidade política: o princípio de igualdade se efetiva por meio do dissenso, que consiste na "ruptura das formas sensíveis da comunidade" (ibid.: 370). Ou seja, o dissenso deve suspender as lógicas hegemônicas sensível e consensualmente estabelecidas como "naturais". Dessa maneira, o dissenso seria o espaço de evidência dos conflitos e, portanto, um conceito bastante próximo da abordagem agonística (Mouffe, 20013), que evidencia o caráter sempre disputado do espaço público.

Cabe apresentar assim uma distinção central produzida por Rancière (2006) entre o conceito de política e polícia: àquilo normalmente compreende-se como a "política", enquanto ordem e gestão social, o autor sugere nomear de "polícia", compreendendo-a como formas amplas de organização e vigilância "da distribuição sensível dos corpos em comunidade" (ibid.: 372). Tal noção impõe uma ordem do que é visível e dizível em determinados espaços sob os quais atua. Por conseguinte, compreende-se "política" enquanto ações heterogêneas que desestabilizam a ordem estabelecida pela polícia. É precisamente nesse ponto que o dissenso se torna próprio da política: “é uma perturbação no sensível, uma modificação singular no que é visível, dizível, contável” (ibid.: 372).

Para pensar adiante na obra de Calle, proponho de antemão a seguinte reflexão: uma manifestação política no espaço público urbano terá distintos significados para a polícia e para a política a partir da conceituação do autor. Do ponto de vista da polícia, toda manifestação corresponde a uma perturbação da ordem, uma vez que a rua é determinada como espaço de circulação, dos automóveis, do deslocamento utilitário; por seu turno, para a política, a atuação sobre o espaço produz tensionamento na natureza e usos do lugar, transformando-o em lócus para os conflitos e disputas sobre a configuração do sensível. Seguindo o caminho da política, apresentarei algumas performances da artista na próxima seção. 
É assim que Rancière (2006) nos permite pensar as ruas e os espaços públicos urbanos como peças-chave para a constituição dos dissensos, uma vez que aquilo que pode ser visto e ouvido nesses espaços é determinado pela polícia. A histórica negação da condição política às mulheres, aos trabalhadores, pessoas racializadas, migrantes, consiste especificamente em sua relegação espacial ao privado que, portanto, garante suas invisibilidades e indizibilidades a partir da separação dos mundos público e privado. Ao mesmo tempo, consiste em uma inadiável recusa de direito à cidade e do direito à cidadania a seus sujeitos marginalizados:

[...] o próprio do dissenso político, como vimos, é que sempre pelo menos um dos elementos da cena não está constituído: seu lugar, seu objeto, os sujeitos aptos a falar dele, etc. Consequentemente, o interlocutor dissensual fala em dois mundos ao mesmo tempo, e a relação argumentativa entre esses dois mundos não é dada senão pela invenção conflitual. (Rancière, 2006: 377, grifos meus)

Mouffe (2013), de maneira muito semelhante, identifica uma diferença entre "política", enquanto espaço do antagonismo e da dimensão conflitual constitutiva de toda sociedade, e "políticas", que consistem nos arranjos institucionais que instauram a ordem hegemônica e os modos de vida dominantes. Insisto nesses pares "polícia-política" e "política-políticas" pois eles são fundamentais à formulação de um pensamento crítico das práticas de planejamento urbano enquanto "polícia-políticas" organizadoras dos espaços públicos nas cidades.

Seguindo pelas teorizações de Rancière (2009) a proposição de uma "partilha do sensível" propõe um sistema que evidencia a existência de um comum compartilhado e partes exclusivas/excludentes. A partilha do sensível nada mais é do que o espaço das visibilidades, pois a política se refere exatamente àquilo que pode ser visto e dito. A relação entre política e estética é abordada como modo de representar esse comum (ibid.), compreendendo que as práticas artísticas podem reconfigurar o comum para produzir novos efeitos de real.

Nesse sentido, afirma-se uma estética na base da política, outorgando às práticas artísticas a capacidade de reconfiguração do mundo sensível. Rancière (2009) identifica três regimes históricos da arte: o regime ético das imagens, o regime representativo ou poético e o regime estético. Trata-se da transição do regime representativo - orientado pelo ideal da mimese ao regime estético - cujas distinções não mais se dão nos modos de fazer interno à esfera da arte, mas a partir da "distinção de um modo de ser sensível próprio aos produtos da arte" (ibid.: 32). Isso significa afirmar o regime estético como 
aquele que pode reorganizar a partilha do sensível que está dada, abandonando o regime mimético para tornar-se potência heterogênea, criativa e que participa do comum.

A partilha do sensível faz ver quem pode tomar parte no comum em função daquilo que faz, do tempo e do espaço em que essa atividade se exerce. Assim, ter esta ou aquela "ocupação" define competências ou incompetências para o comum. Define o fato de ser ou não visível num espaço comum, dotado de uma palavra comum, etc. (Rancière, 2009: 16)

Se a partilha do sensível determina os modos de experienciar e organizar o comum, então as práticas artísticas do regime estético são passíveis de rearranjar as partilhas que estão dadas. Uma vez que a partilha do sensível se refere às visibilidades estabelecidas como possíveis, as disputas políticas serão sempre estéticas, visto que objetivam redefinir os visíveis e os enunciáveis de determinadas sociedades. Assim, as artes "são uma recomposição da paisagem do visível, da relação entre o fazer, o ser, o ver e o dizer. [...] as práticas artísticas não constituem "uma exceção" às outras práticas. Elas representam e reconfiguram as partilhas dessas atividades" (Rancière, 2009: 69).

Cabe salientar um ponto importante: a qualidade pública de uma obra de arte não reside em sua inserção em locais ditos públicos, mas sim se ela transforma aquele espaço a partir de seus usos (Deutsche, 2007). Logo, se a arte é um espaço de representações, ela pode também ser agente na produção dos espaços sob os quais atua (Pallamin, 2000), interagindo em suas disputas.

Desse modo, interessa aqui pensar estratégias artísticas que trazem à mostra o que na partilha do sensível não está visível - que rearticula signos, imagens e significados pré-estabelecidos e normatizados. Tal reorganização condiz com a definição do trabalho da ficção, que altera as formas de apresentar o sensível e os modos de enunciar, elaborando outras novas inteligibilidades. Oportunamente, destaco que não existe um real “em si”, mas somente articulações que produzem efeitos de realidade:

O real é sempre objeto de uma ficção, ou seja, de uma construção do espaço no qual se entrelaçam o visível, o dizível e o factível. É a ficção dominante, a ficção consensual, que nega seu caráter de ficção, fazendo-se passar por realidade (Rancière, 2012: 74).

A ficção também é associada à produção de dissensos, pois interfere nos modos de configurar o sensível, resultando em novas percepções, multiplicando novos enunciados, tornando-se heterotopia. As heterotopias são as utopias localizáveis, um 
termo que produz um lugar localizável a partir da transformação do sensível (ibid.). Assim, se a arte trata de produzir visibilidades, também proporciona modos de pensar o espaço que perturbam os métodos tradicionais de refletir sobre as questões políticas do espaço.

A partir destas considerações teóricas até aqui apresentadas, a seguir são tecidas as análises das contribuições de Sophie Calle na ampliação e redefinição das noções de espaço público, a partir de um entrelaçamento que sua obra nos possibilita à luz desses conceitos acima elaborados.

\section{Calle: Partilhando novos sensíveis}

Nascida em Paris em 1953, Sophie Calle é uma das principais artistas conceituais em atividade na contemporaneidade: produzindo um trabalho bastante peculiar sobre as arbitrariedades da vida cotidiana, a artista tornou-se bastante conhecida pelo minucioso exame da vida privada - sua e daqueles que cruzam seu caminho. Como boa parte dos trabalhos conceituais que evocam a reflexão no momento da interação com a obra, Calle é uma artista multimídia: se vale de seus registros escritos, fotográficos, performances, filmes e ficções resultantes em um conjunto artístico bastante singular que marcam sua produção desde os anos 1970.

Categorizar Sophie Calle no vasto campo da arte conceitual nos demanda, no entanto, tentar elaborar uma genealogia de seus deslocamentos urbanos, afetivos, transnacionais aos quais temos acesso somente por meio de seus registros que são amplamente específicos aos seus contextos de produção. Questões de identidade, voyeurismo, intimidade própria e alheia se tornam insumos centrais no jogo de produção. Dado o escopo desse artigo, que se origina de uma pesquisa especificamente voltada a pensar a vida urbana, realizo um recorte de cinco obras da produção de mais de 40 anos da artista para refletir, junto à sua obra, novos modos de narrar a cidade e borrar fronteiras entre público e privado. A maior parte das obras aqui selecionadas podem ser localizadas na fase inicial da carreira de Calle, mais próxima a sua vertente detetivesca.

Christine Macel (2003) mostra, por meio das entrevistas biográficas realizadas com a artista, que Calle é o oposto da "morte do autor" proposta pelos teóricos pósestruturalistas, tornando-se obra viva, autora, atriz e coadjuvante de suas narrativas que não são nem ficcionais nem factuais, mas um cruzamento de fronteiras constante. Elkin 
(2016) identifica a artista francesa Sophie Calle (1953) como uma flâneuse $e^{4}$ por excelência, uma vez que seus trabalhos das décadas de 1970 a 1990 consistem especificamente em obras produzidas a partir dos insumos da vida urbana cotidiana.

Calle integra o debate deste artigo a partir de uma obra essencialmente conectada às ideias situacionistas de deriva ${ }^{5}$ enquanto modos de se apropriar da cidade, mas que também adentram na discussão sobre a arbitrariedade das noções estáticas de público e privado enquanto esferas separadas. As obras aqui apresentadas consistem em algumas de suas incursões urbanas que engendram transgressões, metáforas e ficções (Rancière, 2009), produzem novas leituras que subvertem a linguagem tradicional do espaço público. Preconizando uma radical complexidade espacial, sugiro que Calle descaracteriza a dicotomia público e privado, tornando as ruas um espaço ambíguo, no qual as fronteiras entre esferas tornam-se, de maneira bastante evidente, borradas.

Encontros aleatórios com pessoas e objetos são, portanto, o motor das ações de Sophie Calle. As banalidades cotidianas se tornam o insumo artístico por excelência, organizados em composições de imagens e textos que nos dão indícios das situações ocorridas. As incursões se iniciam no ano de 1979: sentindo-se deslocada e entediada em sua cidade natal após alguns anos vivendo no exterior, Calle decide passar a seguir pessoas aleatórias pelas ruas de Paris. Sem nenhuma motivação específica declarada para a escolha de seus alvos, a artista segue desconhecidos em seus percursos e itinerários cotidianos. Chama a atenção nessas performances a ausência da artista na maior parte das imagens: ainda que seu engajamento com as ruas seja central à constituição das obras, Calle se torna a observadora da rua, uma flâneuse: ouu ainda uma anti-flâneuse.

Certo dia, durante este período, em uma exposição de arte Calle é apresentada a um homem que ela havia seguido naquele mesmo dia, que dará origem a um de seus mais importantes projetos, chamado Suíte Veneziana (1980), no qual a artista irá à Veneza para segui-lo em uma nova cidade. Posteriormente, desenvolveu diversas séries que partem da experiência urbana que permitem questionar a estabilidade da cisão entre público e privado: em 1981, solicita à sua mãe que contrate um detetive para segui-la na rua e registrar seus movimentos; ao encontrar uma caderneta perdida na rua, inicia uma busca por remontar a identidade de seu dono; em 1994, em parceria com o escritor norte-

\footnotetext{
${ }^{4}$ Flâneuse é uma flexão de gênero de flâneur. Historicamente, o praticante da flânerie é um flâneur, personagem de identidade masculina cuja prerrogativa de poder usufruir e vagar livremente pelas ruas e observar a vida urbana é considera por Wolf (1985) uma experiência masculina.

${ }^{5}$ Sobre as definições de deriva ver Jacques (2003); Internacional Situacionista (2004); Careri (2013).
} 
americano Paul Auster, adota uma cabine telefônica como seu local na cidade. Desse modo, são cinco performances da artista que revolvem sobre o tema da documentação da vida urbana confiantes nas arbitrariedades do cotidiano: Suite Veneziana (1980), The Detective (1981), The Address Book (1983), The Bronx (1980-2002) e The Phone Booth (1994).

A seguir, apresento estas obras ao constatar as tessituras produzidas por Calle, que criam uma relação singular entre subjetividade e alteridade, na qual suas poéticas transitam entre público e privado, ficção e realidade, entre vida e arte (França, 2008). Investida em projetos artísticos que tratam de sua vida cotidiana, seus percursos urbanos e suas vivências pessoais na cidade se tornam seus insumos artísticos de tal maneira que Calle proporciona uma visão de espaço público singular, na qual as fronteiras que seccionam público e privado estão sempre relativizadas em seus relatos.

Os percursos de andanças pela cidade se iniciam na performance To Follow... (1979, sem tradução), em que Calle decide seguir pessoas aleatórias pelas ruas de Paris. Após oito anos vivendo em Nova Iorque, retorna à sua cidade de origem e é tomada por um sentimento de estranheza, como se nunca estivesse estado ali antes: Paris se tornou pouco familiar e ameaçadora: sente-se solitária, sem rumo e tampouco tem amigos. Sem nenhuma motivação declarada, Calle segue estranhos pelas ruas, aos quais escolhe aleatoriamente, deixando seu próprio percurso diário ser determinado ao acaso (Calle, 2007). Eventualmente, começa a registrar esses percursos em fotografias e tomando notas em um diário, método que foi sistematicamente adotado para outras performances subsequentes - Suite Veneziana, The Adress Book e The Detective.

\section{Suíte Veneziana (1980)}

Em Suite Veneziana (1980), Calle produz um amplo registro de sua jornada à Veneza, na Itália, para perseguir um homem - seu pseudo e brevemente conhecido Henri B. - o qual havia sido apresentada em uma exposição em Paris. Segui-lo sem seu conhecimento tornou-se o projeto: a ação consistia em uma investigação e em excursões diárias por Veneza atrás de Henri B. Disfarçada com uma peruca loira, Calle insistentemente busca descobrir o hotel no qual seu alvo estava hospedado, empreendendo uma rica ação de registros em um diário dos locais visitados por ele, com tempo de permanência, fotografias e mapas de seus trajetos. 
A perseguição se inicia dia 11 de fevereiro de 1980, encerrando-se treze dias mais tarde, em 24 de fevereiro, no mesmo local: a estação de trem Gare de Lyon em Paris. Incialmente, Calle relata quatro dias de investigação no diário antes de finalmente conseguir localizar Henri B: telefona para todos os hotéis e pensões da cidade, conversa com pessoas locais, como Pino, um caricaturista veneziano que promete ajudá-la e para quem ela afirma estar buscando um amigo. Às 18:45 do dia 15 de fevereiro, Calle finalmente encontra a pensão em que Henri B. está hospedado, casualmente localizada a apenas de 100 metros de sua pensão.

A partir de uma fotografia de uma cena trivial: um homem e uma mulher, de costas, olhando uma vitrine de uma loja de bolsas - Calle comemora e nos mostra a sua pequena vitória. $\mathrm{Na}$ imagem que registra um dia de sorte em seu diário de perseguição a Henri B., esta aparece na entrada do dia 18 de fevereiro, às 18:00, dia no qual o havia seguido desde às 10:05 da manhã. O seguinte trecho acompanha a fotografia:

\footnotetext{
Ele se levanta, desaparece por dois minutos, retorna e paga. Eles deixam o café. A noite caiu. Minha sombra continua: Piazza San Marco - eles olham para a loja Pauly e C., vidro veneziano - Calle dell'Ascension - eles olham um pouco mais as bugigangas na Bertoli, então eles param por cerca de três minutos na frente da vitrine em Vogini, loja de sapatos e bolsas. Volto minhas costas a eles e observo seus movimentos através do reflexo da vitrine, no outro lado da rua Calle della Frezzeria, Piscina di Frezzeria - um beco obscuro e deserto que se alarga em uma pequena praça. Nós estamos sozinhos, eu estou perto dele, ele não me assusta. (Calle, 2015, s.p., tradução minha)
}

Às 18:15 desse mesmo dia - conforme registro do diário - Henri B. e a mulher entram em um antiquário, e Calle permanece por mais de duas horas repletas de relatos impacientes da artista aguardando-os na rua fria no anoitecer de um dia de inverno. Ao longo de todo o dia 18 de fevereiro, Calle conseguiu persegui-los, fornecendo-nos um mapa do trajeto que os três realizaram (Figura 1). A ação artística de seguir um homem, escolhido ao acaso devido à coincidência de encontrá-lo duas vezes no mesmo dia em Paris, resulta nesse relato de um jogo investigativo, de uma conexão ímpar com a cidade veneziana a partir de uma perseguição um tanto quanto peculiar. Calle afirma não ter nenhum interesse particular, amoroso ou sexual em Henri B - ela está alucinada por sua perseguição, mas suas motivações parecem remeter somente ao próprio desejo de movimentação na acossa. 


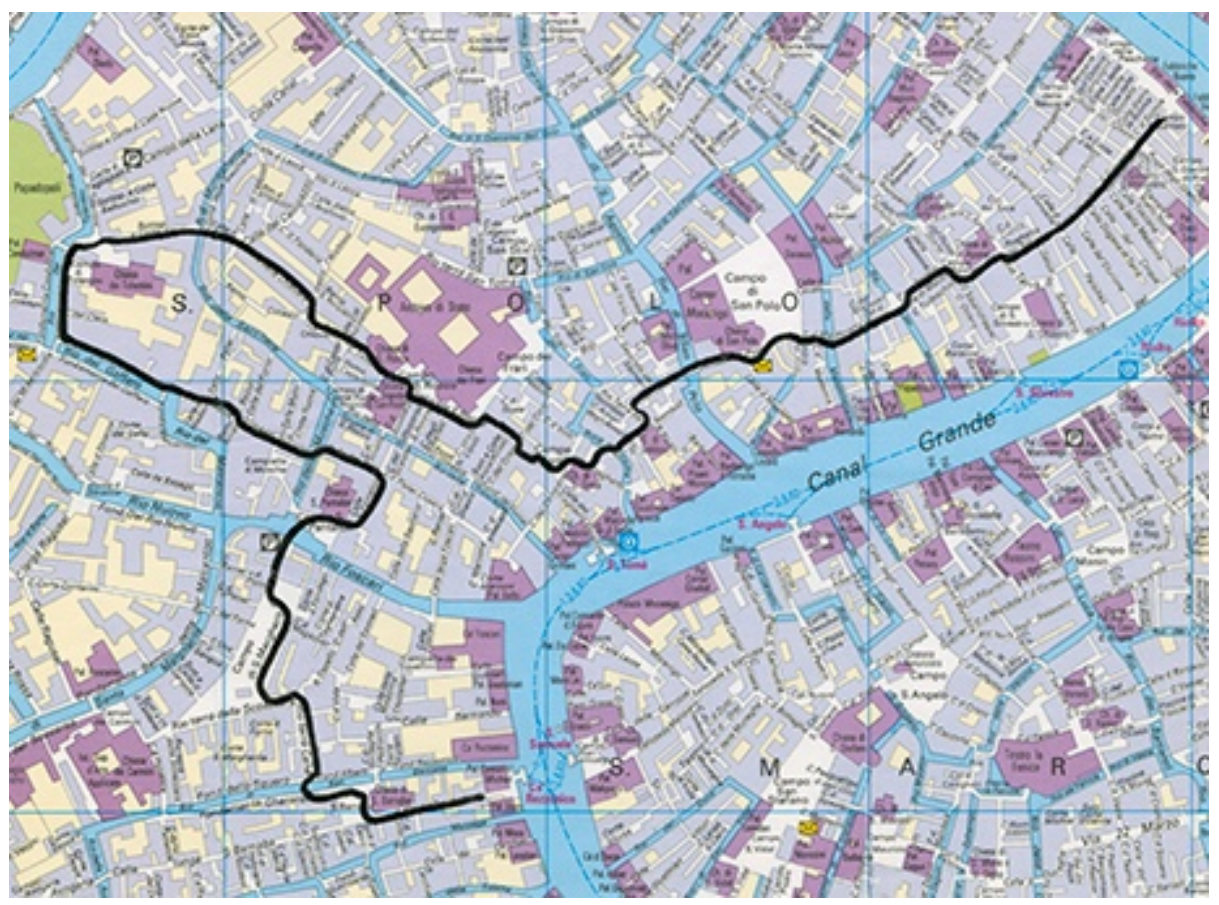

Figura 1 - Sophie Calle (2015). Mapa da perseguição de 18 de fevereiro de 1980. Reprodução: Siglio Press.

Disponivel em: http://sigliopress.com/book/suite-venitienne/

A imagem do mapa nos remete ao primeiro dia em Veneza, no qual escreve em seu diário: "Eu me vejo na entrada do labirinto, pronta para me perder na cidade e nesta história. Submissa." (Calle, 2015, s.p.). A intenção da artista, se é que é possível inferila, parece ser a desorientação que cidade pode proporcionar, descobrindo-a de modo involuntário, a partir de um itinerário que é ora imposto por sua investigação, ora imposto pelos caminhos que Henri $\mathrm{B}$ decide tomar. Calle desfruta de uma experiência avessa à turística, apresentando-nos um espaço descontínuo - não segue os pontos marcados por um guia de turismo, pois os pontos a serem percorridos são fornecidos por meio de Henri B e, portanto, são sempre imprevisíveis. A partir da noção de labirinto, Calle remete sua obra a Walter Benjamin (1986) que via na prática da flânerie o espaço da metáfora do detetive, que na cidade-labirinto se confronta com o inesperado, que circula pelo inesperado na figura da viajante por excelência.

No dia seguinte a localização de seu alvo, 19 de fevereiro de 1980, há também um longo registro sobre a perseguição do dia, mas, de repente, Henri B. parece notar a presença de Calle, disfarçada com uma peruca loira. Frustradamente, tenta despistá-lo, que finalmente a encontra cara a cara como mostra registro do diário:

Eu abro meus olhos; ele está na minha frente, muito próximo. Estamos sozinhos [...] ele está tentando lembrar? Então ele fala: eu reconheço seus olhos: isto era o que você deveria ter escondido. Ele dá um passo atrás para me fotografar. Ele 
sugere: 'Você gostaria de caminhar junto?' Eu sinalizo que sim. (Calle, 2015, s.p.)

A imagem de um homem tentando tapar a câmara fotográfica com Veneza ao fundo, é o que Calle nos apresenta do momento desse encontro, tentando fotografar seu rosto sem sucesso. Caminham juntos pela cidade, em silêncio, e depois se despedem. Depois desse momento, a artista não volta a perseguir seu alvo: em vez disso, retorna ao antiquário no qual esperou por horas e conversa com o dono da loja e perguntar por Henri B. Pouco tempo depois, Calle decide retornar a Paris no mesmo trem que Henri B: nesse momento, tira uma última fotografia e encerra esse capítulo de sua história.

\section{The Address Book (1983)}

Seguindo na produção de performances persecutórias, a imagem de uma caderneta de endereços caída na rua - mas poeticamente posicionada sobre um pé metálico de uma mesa ou outro mobiliário urbano - refere-se ao trabalho The Address Book, de 1983. A performance é iniciada a partir de um objet trouvé, um tema caro ao surrealismo, no qual um objeto cotidiano encontrado casualmente adquire potencial valor estético a partir de sua deliberada transformação em arte. Próximo à ideia duchampiana de ready-made, o objeto enfatiza a potência do acaso e do voyeurismo presentes nos trabalhos de Calle.

Deambulando pela cidade, Sophie Calle se depara com a agenda telefônica perdida e decide romper com as prerrogativas burguesas implicadas nas normas de respeito à privacidade: seu plano é fotocopiar a agenda, devolvê-la ao proprietário e então telefonar para todos os seus contatos a fim de conhece-lo por meio dos relatos de seus amigos e conhecidos. Tudo o que Calle sabe sobre seu alvo é que a agenda pertence a Pierre D., devido à identificação na página inicial do objeto. Novamente movida por suas motivações incógnitas, tenta marcar encontros com as pessoas listadas a fim de produzir um retrato falado de Pierre D. (Calle, 2012), visitando a casa dessas pessoas, encontrando em cafés e bares em diferentes locais da cidade parisiense.

Assim, o objeto encontrado dispara uma experiência estética: Calle perde-se entre os relatos que ouve, mas também na cidade, perseguindo suas informações valiosas mas que aparentam ser desprovidas de sentido para serem buscadas com tanto afinco. Sophie Calle toma notas, replicando-as em seu formato habitual de diário: uma fotografia e um texto que informa o dia da semana, nome do contato, horário de encontro, o local onde encontrou a pessoa, quais informações essa pessoa forneceu sobre Pierre D. 
Este trabalho é um exemplar modo de deriva, desta vez norteado pela busca de tornar pública a vida pessoal de alguém, mas também de relativizar as fronteiras de vida pública e privada em termos amplos ${ }^{6}$. A vontade de produzir a história de Pierre faz a artista se deslocar pela cidade, conhecer desconhecidos, expandir os termos de espaço público e privado, atualizando reorganizando as distinções binárias (Cortés, 2008).

\section{The Detective (1981)}

Em uma fotografia da artista, sentada em um café ao ar livre e capturada de longe, temos uma situação inversa: de perseguidora à acossada, nessa obra Sophie Calle solicita a sua mãe que contrate um detetive particular para segui-la na cidade, por um dia, reportando todas suas atividades cotidianas a fim de produzir "evidências fotográficas" de sua existência (Calle, 2007). Sem que o detetive soubesse de sua consciência de estar sendo seguida, o livro da artista nos dá acesso a dois registros paralelos: os escritos de Calle, nos quais relata sua rotina na forma narrativa de um diário, e o relatório preciso, objetivo e (im)parcial do detetive. Ao acessar essas duas fontes, temos informações divergentes - ela afirma comprar calêndulas na floricultura e jornais no Boulevard EdgarQuinet, ao passo que o detetive registra que ela comprou narcisos-amarelos na floricultura e jornais na banca no Boulevard Respail, número 202. Aqui, Calle demonstra seu completo desprezo para com a factualidade do que narra: jogando entre a objetividade do observador e a subjetividade de sua experiência vivida, a finalidade desses relatos revelam que o interstício entre real e ficcional são precisamente os subsídios da obra.

Quinta-feira, 16 de abril, 1981. 10h00: Estou me preparando para sair [...] Às 10:20 eu saio [...] O clima está limpo, ensolarado. [...] Eu tomo a rua Gassendi e compro calêndulas por 8 francos na floricultura. Eu entro no cemitério Montparnasse e deixo as flores no túmulo de Pierre V. [...] Todos os dias, por anos, quando eu ia ao colégio, eu pegava a mesma rota. [...] $\mathrm{Na}$ saída do cemitério, no Boulevard Edgar-Quinet, eu compro Le Monde e Pariscope. Às 10:40 eu vou ao La Coupole, 102 Boulevard de Montparnasse, onde eu tenho um encontro com Nathalie M. [...] Às 11:30, nós saímos do La Coupole, Nathalie caminha comigo até o cabeleireiro na rua Delambre. É para "ele" que estou arrumando meu cabelo [...] Então eu caminho em direção aos Jardins de Luxemburgo, eu quero mostrar a "ele" as ruas, os lugares que eu amo. Eu quero que "ele" esteja comigo enquanto eu atravesso o Luxemburgo, onde eu brincava quando criança e onde eu recebi meu primeiro beijo na primavera de 1968. Eu continuo com meus olhos baixos. Eu tenho medo de vê-'lo'. (Calle, 2007: 124)

\footnotetext{
${ }^{6}$ Vale destacar que este trabalho só pode ser publicado em 2012, após a morte de Pierre D. Após descobrir o trabalho de Calle realizado a partir de sua história, o homem ameaçou processar a artista. Disponível em: https://www.huffpost.com/entry/sophie-calle-address-book-controversy-siglio-press_n_2271871
} 
Em contraste, no relatório do investigador, seus excertos mostram uma forma de narrativa completamente diferente: “Às 11:32, o indivíduo sai do prédio na companhia de uma amiga de aproximadamente 27 anos, 1,65m de altura, de constituição robusta, cabelo longo castanho, usando uma calça marrom clara e um suéter preto" (Calle, 2007: 131).

O excerto de Calle, que coloca sua experiência e subjetividade sobre os espaços da cidade, testemunha como os espaços públicos que atravessa são também espaços da sua memória afetiva: seu caminho diário durante a infância, as ruas que ama, o local onde deu seu primeiro beijo. Em alguma medida, são espaços ressignificados por suas experiências, sempre singulares e particulares. Calle tem uma preocupação narrativa, ao passo que o detetive dispõe de uma abordagem factual, descritiva, impessoal e se refere sempre à perseguida como "o indivíduo" - the subject, na versão em inglês. Ao passo que a descrição do detetive é sempre objetiva e utilitária, a de Calle é subjetiva, poética e narrativa, revelando tanto um embaralhamento entre real e ficcional quanto as diversas maneiras de relatar a experiência urbana.

\section{The Bronx (1980)}

Em 1980, Calle vira sua jornada urbana a um lócus social e urbanisticamente marginalizado - o sul do Bronx nova-iorquino, de população prioritariamente afrodescendente, migrante e de precárias condições socioeconômicas. Abordando pessoas desconhecidas nas ruas, Calle pedia para que estas a levassem a um local que escolhessem e considerassem especial no bairro. Nesses locais, a artista fotografava seus interlocutores e fazia anotações sobre aquilo que lhe relatavam.

Em uma das imagens, há uma mulher negra, de cabeça raspada, apoiada no parapeito de uma ponte que cruza uma passarela e um matagal descuidado; em outra, há um homem jovem que olha para a câmera em meio a um aterro, no qual vemos uma série de grandes edifícios idênticos ao fundo. Para este trabalho, não foi possível ter acesso aos registros escritos da artista sobre a série, mas, ainda assim, a obra integra este artigo pois evocam um imaginário urbano distinto das demais.

Em primeiro lugar, a técnica de abordagem de Calle se torna definitivamente diferente das outras séries, uma vez que os indivíduos consentem conscientemente em participar do trabalho. Há, de maneira distinta dos trabalhos de perseguição, um olhar etnográfico presente nessas imagens que se apoia em informantes locais para navegar em 
um espaço no qual ela é novamente uma outsider. Em segundo lugar, a paisagem urbana trazida à tona pelas imagens põe em evidência um bairro empobrecido, resultante de um abandono do poder público e de uma deliberada segregação urbana promovida pela construção da via expressa Cross Bronx, empreendida pelo engenheiro Robert Moses. Findada a construção, no início da década de 1970, temos como resultado um distrito dilacerado pelo deslocamento massivo de moradores economicamente vulneráveis (Berman, 1986).

Esses retratos de Calle documentam um ambiente urbano ermo, pauperizado e, quando em relação a outras imagens de Nova Iorque, evidenciam um espaço que é deliberadamente resultante de política pública engajada em estratégias de diferenciação das distintas áreas da cidade que operam uma exclusão constitutiva (Deutsche, 2008) de determinados perfis sociais e étnico-raciais para produzir espaços de margem e espaços centrais. Calle opera a razão de uma atriz ocasional, como nos fala Rancière (2006): constrói cenas singulares, sempre ameaçadas de desaparecer mas que reorganiza o sensível e amplia as compreensões possíveis daquele espaço sobre o qual fala.

\section{Phone Booth (1994)}

Por fim, em um cenário urbano nova-iorquino diametralmente oposto ao de The Bronx (1980), Calle elege uma cabine telefônica em uma área movimentada e comercial de Manhattan na série Phone Booth (1994). O trabalho consiste em uma colaboração com o escritor norte-americano Paul Auster, que se inspirou na vida e obra de Calle para compor sua personagem, a artista Maria Turner, no livro "Leviatã”, publicado em 1992. Phone Booth é uma série que resulta de "Instruções Pessoais para S.C. sobre como melhorar a vida na cidade de Nova York (porque ela pediu...)" que Auster fornece à artista, como parte de um jogo que inverte a posição da artista de personagem do livro inspirada em si, tornando o escritor autor de suas ações (Fabris, 2009).

Em uma das instruções, Auster ordena-a a fazer sanduíches e comprar cigarros para distribuir a moradores de rua. Em outra instrução, sugere o cultivo de um lugar (cultivating a spot): Calle deve eleger um lugar na cidade para chamar de seu: "Escolha um lugar na cidade e comece a pensá-lo como seu” (Auster apud Calle, 2007: 244). O lugar pode ser qualquer um, seja uma esquina, um banco, uma árvore, mas Calle deve se 
responsabilizar por ele, mantendo-o limpo, bonito: "Pense nele como uma extensão de você, como parte de sua identidade" (ibid.). De acordo com as diretrizes, Calle deve ir ao local todos os dias, ficar lá por uma hora e registrar tudo que acontece em fotografias e escritos, buscando aprender algo sobre si, sobre o lugar, sobre as pessoas; também deve sorrir aos transeuntes, conversar com elas sempre que possível, podendo iniciar a conversa a partir da previsão do tempo.

Por seu turno, Sophie Calle escolhe uma cabine telefônica na esquina da rua Greenwich com a rua Harrison, ponto localizado na Baixa Manhattan. Para decorá-la, compra produtos de limpeza, um cinzeiro, duas cadeiras dobráveis, cartões postais, um espelho, flores, uma revista, tinta com a qual pinta de verde o chão e as bordas da cabine (cobrindo o logotipo da companhia telefônica). Na noite do dia 20 de setembro de 1994, inicia seu trabalho de limpeza e polimento de sua cabine, quando dois homens que passam perguntam a ela se também limpa janelas: no diário, Calle se pergunta se já deve começar a tarefa de sorrir para as pessoas, mas decide adiá-la para o dia seguinte: "Eu não respondo pois, Paul, como você mesmo diz, homens são porcos" (Calle, 2007: 246). E continua: “Apenas cinco minutos após eu ter começado, meus medos se confirmam: eles estão me achando louca. Que pena".

Iniciando sua performance no dia seguinte, às $12 \mathrm{~h}$, a primeira coisa que percebe é que dois homens - os mesmos da noite anterior - haviam se tornado cinco, levando-a a crer que a esquina era "deles" (ibid.). Ao longo dos dias, registra todos os seus "visitantes" toma nota das conversas telefônicas alheias, contabiliza quantos homens e mulheres param para olhá-la, bem como quantas pessoas perguntam se ela está "encarregada" da cabine. Quando Calle responde negativamente, comentam que sua intervenção "é vandalismo"; outros ainda se perguntam se a cabine tornou-se local cativo de algum morador de rua. Certo dia, uma mulher, presidente do conselho comunitário, aborda a artista para perguntar-lhe se ela tem permissão para fazer aquilo: Calle não responde. No dia 27 de setembro, uma semana após o início da performance, Calle coloca um bilhete em cima do telefone lamentando o fim de suas atividades:

Sentimos muito por informá-lo de que não poderemos mais continuar a servir você. Na terça-feira, 27 de setembro, às 09h30, alguns agentes da AT\&T puseram fim a tudo, ameaçando-nos e colocando os arranjos (flores, jornais, revista, caneta e papel, bebidas, cigarros, etc.) no lixo. Agradecemos muito por ter usado nossos serviços e pela generosidade de seus comentários. Adeus. (Calle, 2007: 288) 
Esse trabalho de Sophie Calle parece se constituir como uma ficção artística e política que, nos termos de Rancière (2012: 74), "sulcam, fraturam e multiplicam esse real de um modo polêmico". O real é, então, transformado em múltiplas possibilidades, dentre elas, usar a cabine como espaço de lazer, do ócio e não apenas por sua utilidade telefônica. Calle evidenciou, a partir de uma reordenação no espaço da cabine onde se situou, como o dissenso "é um conflito sobre a própria configuração do sensível. [...] põe na rua um espetáculo que não têm aí seu lugar” (Rancière, 2006: 373).

Nas incongruências entre relatório e narrativa, é possível constatar que toda a obra de Calle é permeada pela incerteza entre fatos e ficções, ou melhor: o conjunto da obra é permeado ativamente pela relativização das fronteiras que fixam sentidos distintivos entre realidade e ficção, público e privado, identidades e diferença. Como vimos, nesta obra Sophie Calle e Maria Turner se misturam, evidenciando uma arbitrariedade nessas definições que são recorrentemente objetos de atenção da artista.

$\mathrm{Na}$ relativização das fronteiras entre ficção e realidade, cabe retomar Rancière (2009), para quem ficção se trata de algo essencialmente positivo, pois não consiste em apresentar engodos, mas sim em elaborar novas estruturas de inteligibilidade. O que denomina como revolução estética consiste na precariedade da cisão entre a razão das ficções e a razão dos fatos, pois o real deve ser ficcionado para adquirir inteligibilidade, para ser pensado. Logo, ficção e fatos passam a pertencer a um regime de sentido comum. A ficção, na era estética, define modos de conectar os fatos aos modos de inteligibilidade, permitindo a suscetibilidade da fronteira entre razão dos fatos e das ficções. A inseparabilidade da política e da arte permite afirmar que ambas são produtoras de ficções, de modo semelhante a quaisquer saberes, pois operam "rearranjos materiais dos signos e das imagens, das relações entre o que se vê e o que se diz, entre o que se faz e o que se pode fazer" (ibid.: 59).

Como vimos em todas as obras até aqui, Calle é uma contadora de histórias que são, ao mesmo tempo, reais e ficcionais, pois o trabalho da artista não permite formar certezas, apenas se abre ao múltiplo. Em todas as suas performances apresentadas neste trabalho, a artista atua ressignificando o sentido da rua, seus usos e o utilitarismo com o qual pensa-se a cidade, inserindo a estética política como método de pluralização do público. Propõe, nessas práticas, outros modos de se relacionar com a cidade, inspirada nas vivências, narrativas e apropriação dos espaços que pouco suscitam atenção. Ao criar histórias sobre o Bronx, sobre uma cabine telefônica, sobre uma Paris e uma Veneza que 
só são possíveis a partir das perseguições, Calle cria seus contra-espaços, desestabilizando e desafiando a hegemonia dos espaços que são estrategicamente planejados e ordenados.

Cabe destacar novamente que a ficção, tão explorada por Calle, não se refere à invenção imaginária de um mundo oposto ao mundo real, mas a uma reconfiguração do sensível. É a proposição dos dissensos que interfere nas formas de enunciação, permitindo criar outras e novas relações que transformam o que é representável e o que deve permanecer à margem. As nuances de insensatez, e sobretudo de anti-utilitarismo, que permeiam as obras de Calle, apontam para essas ficções, produzindo heterotopias situáveis a partir da reconfiguração da partilha do sensível (Rancière, 2009).

\section{Considerações Finais}

Como busquei elaborar, a arte de Sophie Calle desponta como um vetor para investigar espaço público, produzindo transformações nos modos de pensar e ocupar o espaço público, tanto de um ponto de vista material e espacial quanto conceitual e imaginário, funcionando como estratégias de evidenciação dos limites políticos do espaço e das possibilidades de ação sobre a cidade. Como sugeriu Campany (apud Fabris, 2009: 79), Calle pode ser considerada uma artista contemporânea próxima ao movimento situacionista, dadas suas incursões a "um aproveitamento revolucionário do acaso como forma de ruptura com hábitos urbanos diários". Suas performances suscitam pensar o papel que a arte pode desempenhar no questionamento da aparência democrática dos espaços públicos, trazendo à tona seu caráter inerentemente agonístico, instaurando aquilo que escapa, no qual o diferente opera como norma de seus registros.

A partir das performances aqui apresentadas, busquei evidenciar como a obra de Calle trata, a todo momento, o espaço público como privado e o privado como público a tal ponto que elimina a possibilidade de estabelecermos um ponto referencial. Seu radical engajamento com o atravessamento das fronteiras, também entre real e ficcional, resulta em narrativas públicas que dão densidade à noção de dissenso de Rancière: ao perturbar os modos de configurar o sensível, a obra de Calle produz novos enunciados sobre a cidade, sobre explorá-la como parte do ócio e do jogo - como um uso do espaço urbano que é da ordem da lúdica e não utilitária. As obras aqui apresentadas são produtoras de heterotopias, como bem elaboraram Rancière (2012) e Foucault (2003): são 
as utopias localizáveis a partir da transformação de sensível de um espaço em algo outro. Em seus deslocamentos e negociações, Calle nos mostra como as coisas sempre pode ser de outro modo: outras relações são possíveis com o espaço público urbano, ao embaralhar as ordens de seus usos, novas possibilidades emergem.

Se o lugar na cidade que elege na cidade é "seu", então temos um espaço que é público e privado ao mesmo tempo. Se expõe como arte um local estimado por um morador do Bronx, então, está publicizando algo que consideramos privado, tratando-o como público. Assim, em Calle temos uma evidenciação de que a separação entre público e privado não é mais que uma simplificação das funções sociais de cada espaço, minando a compreensão de público dentro dos parâmetros normativos. Nessas performances furtivas, aqui apresentadas em conjunto, procurei pôr à mostra como sua obra emana em contraponto à uma ordem, à hegemonia dos modos de existência nos espaço públicos mas propõem, a todo tempo, outros modos de estar na cidade: operam em conjunto o agonismo, a partilha do sensível e o dissenso.

\section{REFERÊNCIAS}

ARENDT, Hannah. A condição humana. Trad. Roberto Raposo. 10.ed. Rio de Janeiro: Forense Universitária, 2007 [1958].

BENJAMIN, Walter. Parigi capitale del XIX secolo. Torino, Einaudi, 1986.

BERMAN, Marshall. Tudo que é sólido se desmancha no ar - A aventura da modernidade. São Paulo: Companhia das Letras, 1986.

CALLE, Sophie. Double Game with the participation of Paul Auster. London: Violette Editions, 2007.

. The Address Book. Los Angeles: Siglio, 2012.

. Suite Vénetienne. Los Angeles: Siglio, 2015.

CARERI, Francesco. Walkscapes: o caminhar como prática estética. São Paulo: Editora G. Gili, 2013. 
CIDADE, Daniela Mendes. Os cortes de Gordon Matta-Clark : um ritual de destruição e reconstrução da arquitetura. Tese (doutorado). Universidade Federal do Rio Grande do Sul - Faculdade de Arquitetura - PROPAR. Porto Alegre: 2010.

CORTÉS, José Miguel G. Políticas do espaço: arquitetura, gênero e controle social. São Paulo: Editora Senac São Paulo, 2008.

DAWSEY, Jill Christina. The uses of sidewalks: women, art and urban space, 1966-80. Tese de Doutorado em História da Arte. Stanford University, 2008.

ELKIN, Lauren. Flâneuse: Women Walk the City in Paris, New York, Tokyo, Venice, and London. Farrar, Straus and Giroux: Nova Iorque, 2016.

FABRIS, Annateresa. Sophie Calle: entre imagens e palavras. Revista Ars USP. v. 7, n. $14,2009$.

FOUCAULT, Michel. Outros espaços. In: Ditos e escritos III - Estética: Literatura e pintura, música e cinema. Rio de Janeiro: Forense Universitária, 2003, p. 411-.422.

FRANÇA, Claudia. Estratégias para não se perder na cidade Derivas urbanas de Sophie Calle. Revista Arte \& Ensaios, nº 17, p.85-92, 2008.

FRASER, Nancy. Rethinking the public sphere. A Contribution to the Critique of Actually Existing Democracy. In: Social Text, No. 25/26, pp. 56-80. [1990] 2013.

GARCIA, Carolina Gallo. Gênero da Cidade em Disputa: Práticas artísticas como manifestação do dissenso. Dissertação (Mestrado). Universidade Federal do Rio Grande do Sul. Programa de Pós-Graduação em Planejamento Urbano e Regional. Porto Alegre, 2018.

INTERNACIONAL SITUACIONISTA, Textos íntegros en castellano de la revista Internationale Situacionniste (1958-1969). Madri: Traficantes de Sueños, 2004.

HABERMAS, Jürgen. Mudança estrutural da esfera pública: investigações quanto a uma categoria da sociedade burguesa. Tradução: Flávio R. Kothe. Rio de Janeiro: Tempo Brasileiro, 2003 [1962].

, J. The theory of communicative action. Vol 1. Reason and the rationalization of society. Boston: Beacon Press, 1984.

JACQUES, P. B. (org.). Apologia da Deriva. Escritos situacionistas sobre a cidade. Rio de Janeiro: Casa da Palavra, 2003. 
MACEL, Christine, 'Le Author Issue in the Work of Sophie Calle' in: Sophie Calle: M'as-tu vue, Prestel, Munich, 2003.

MCCLINTOCK, Anne. Couro imperial - raça, travestismo e o culto da domesticidade. In: Couro imperial: raça, gênero e sexualidade no embate colonial. Campinas: Editora da Unicamp, 2010.

MOUFFE, Chantal. Quais espaços públicos para práticas de arte crítica? In: Arte \& Ensaios. Revista do Programa de Pós-Graduação em Artes Visuais - EBA / UFRJ. Rio de Janeiro: PPGAV-EBA/UFRJ, ano XXI, número 27, 2013.

. Feminismo, ciudadanía y política democrática radical. In: Feminists

Theorize the Political, ed. Judith Butler, Joan W. Scott, Routledge, 1992.

. O Regresso do Político. Lisboa: Gradiva, 1996.

. Prácticas artísticas y democracia agonística. Museu d'Art Contemporani

de Barcelona Servei de Publicacions de la Universitat Autónoma de Barcelona. Barcelona; Bellaterra (Cerdanyola del Valles), 2007

NEGT, Alexander, KLUGE, Oskar. The Public Sphere and Experience: Toward an Organizational Analysis of Proletariat and Middle-Class Public Opinion. Minneapolis: University of Minnesota Press, 1993.

PALlAMIN, Vera M. Arte Urbana; São Paulo: Região Central (1945 - 1998): obras de caráter temporário e permanente. São Paulo: Fapesp, 2000.

PATEMAN, Carole. Feminist Critiques of the Public/Private Dichotomy. in: The Disorder of Women. Democracy, Feminism and Political Theory, Cambridge: Polity Press, 1989

RANCIÈRE, Jacques. O dissenso. In: A crise da razão. Org: NOVAES, Adauto. São Paulo: Companhia das Letras; Brasília, DF: Ministério da Cultura; Rio de Janeiro: Fundação Nacional de Arte, 2006 [1996].

RANCIÈRE, Jacques. O espectador emancipado. São Paulo: WMF Martins Fontes, 2012

RANCIÈRE, Jacques. A partilha do sensível. São Paulo: EXO experimental org.; Ed. 34, 2009.

RECKITT, Helena; PHELAN, Peggy. Art and Feminism. New York City: Phaidon Press, 2001. 
SENNETT, Richard. O Declínio do Homem Público: as tiranias da intimidade. São Paulo: Companhia das Letras, 2014 [1974].

SHEIKH, Simon. In the Place of the Public Sphere? Or, the World in Fragments, 2004. Disponível em: http://eipcp.net/transversal/0605/sheikh/en Acesso em 09 de janeiro, 2021.

WOLFF, Janet. The Invisible Flâneuse: Women and the Literature of Modernity. Theory, Culture and Society, v 2, p. 37-48. London, 1985.

Recebido: 05/03/2021

Aprovado: 04/06/2021 